



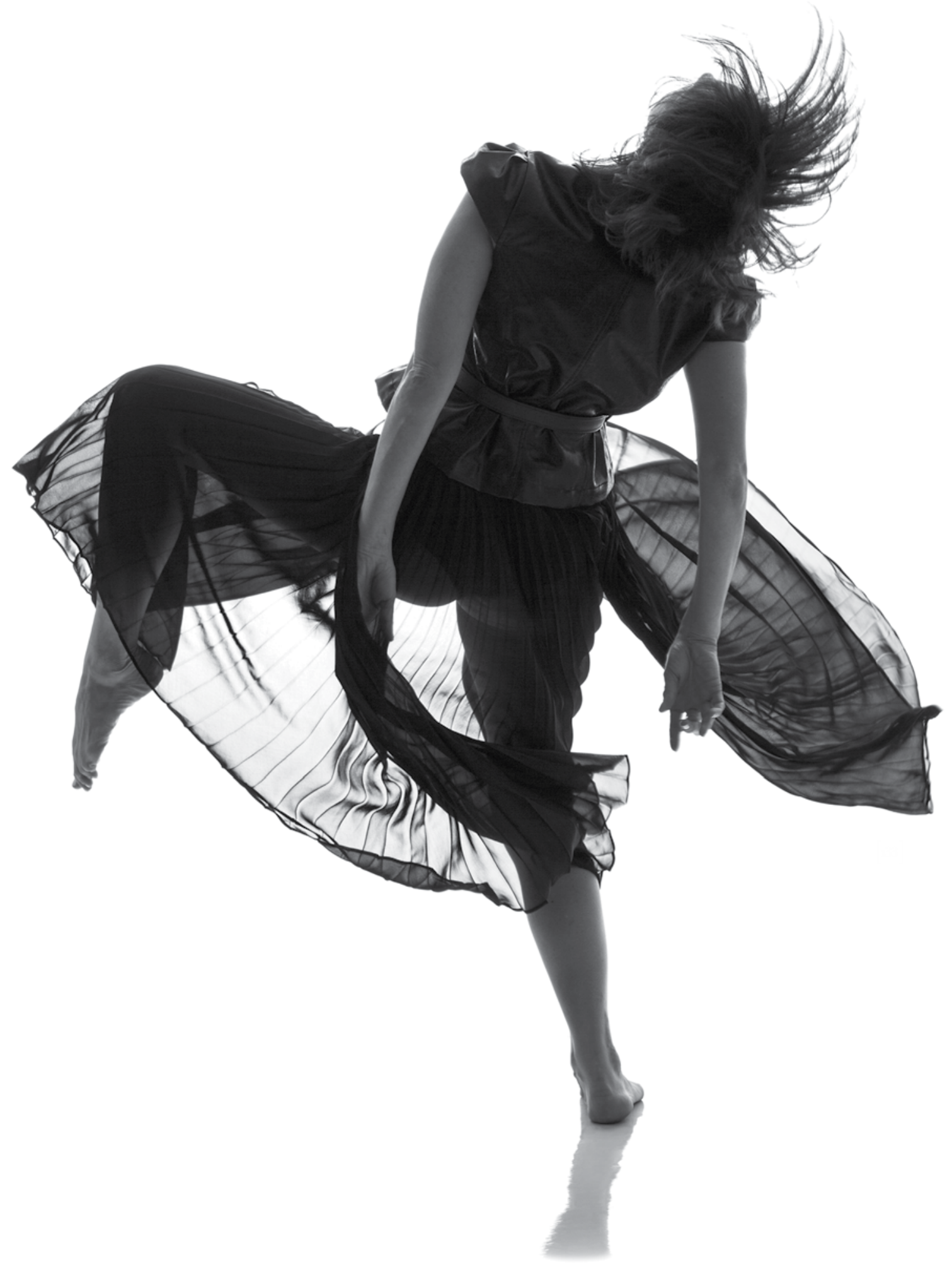


resenha $]$

[ DÉBORA KRISCHKE LEITÃO ]

Doutora em Antropologia Social pela UFRGS com estágio sanduíche junto ao Institut d'Histoire du Temps Présent (CNRS) e professora do Programa de Pós-Graduação em Ciências Sociais da UFSM.

E-mail: deborakl@ufsm.br

\section{Trânsitos da moda brasileira}

Resenha de: MICHETTI, Miqueli. Moda brasileira e mundialização. São Paulo:

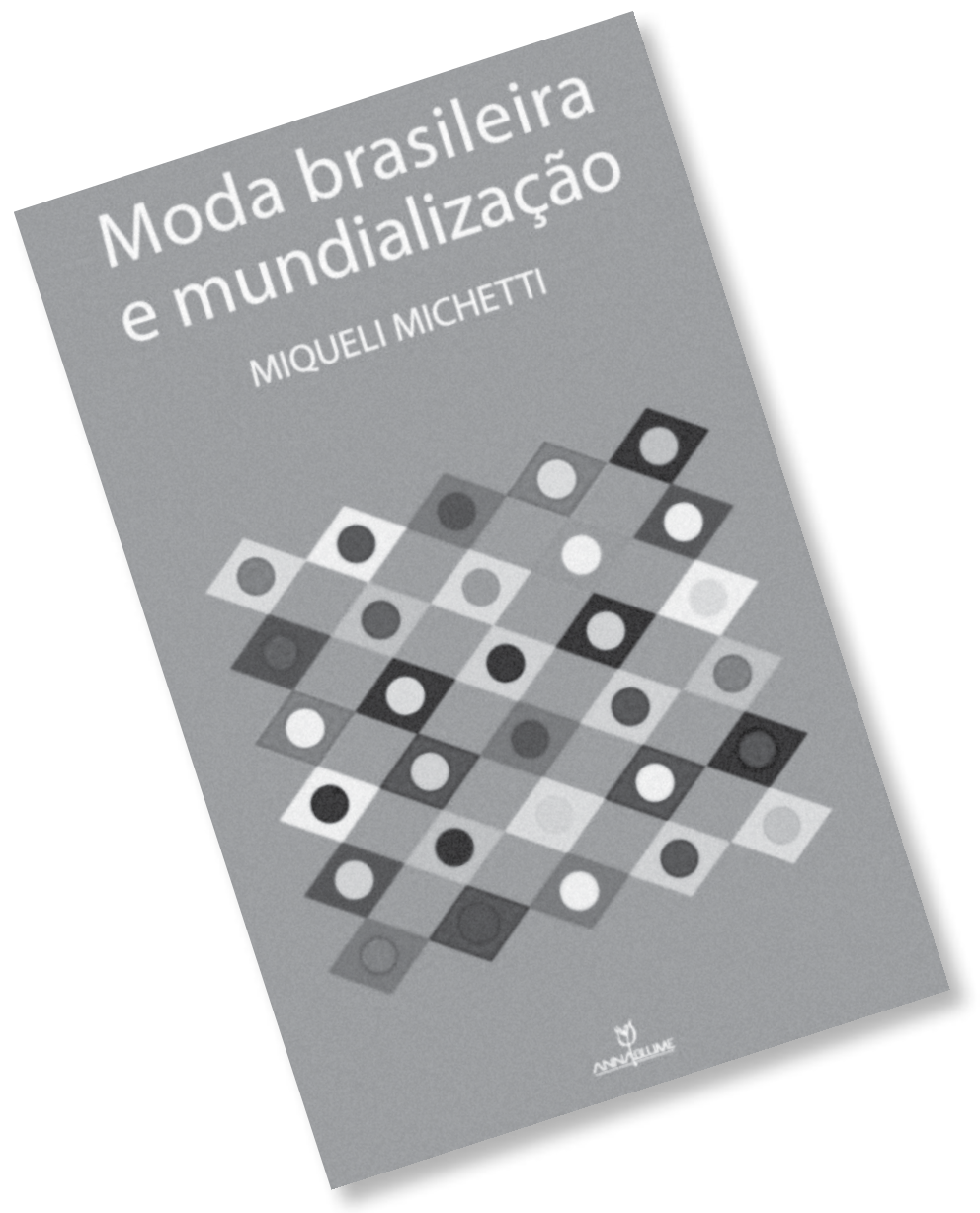


Na última década observamos um crescimento significativo dos estudos acadêmicos sobre Moda no Brasil, não apenas às margens de disciplinas mais tradicionais, como História, Literatura e Ciências Sociais, como outrora, mas dando forma a um campo relativamente autônomo de conhecimento. Podemos dizer que o primeiro Colóquio de Moda, em 2005, o nascimento da revista dObra[s], em 2007, e a produção de um grande número de teses, dissertações e livros sobre o tema, datados dos primeiros dez anos do século XXI, marcaram a consolidação dos estudos sobre Moda no Brasil de maneira definitiva. É nesse cenário de amadurecimento da moda enquanto objeto de reflexão que surge o livro Moda brasileira e mundialização, de Miqueli Michetti, fruto de sua tese de doutorado em Ciências Sociais, defendida em 2012.

Em seu livro, a autora nos mostra como se deu a construção disso que podemos chamar de Moda brasileira, relacionando tal construção com processos globais mais amplos, nas esferas econômica, política e cultural. Tomando a moda como indústria e mercado de bens simbólicos, Michetti analisa o surgimento da Moda brasileira a partir da globalização do próprio campo da moda.

É sabido que a moda europeia, sobretudo francesa, ocupou lugar central historicamente enquanto foco produtor e difusor de tendências. Durante sobretudo a segunda metade do século $X X$, no entanto, o campo sofreu transformações significativas no que diz respeito à sua profissionalização, profundamente marcada pela industrialização e pelo desenvolvimento do prêt-à-porter. Esse é um dos processos descritos pela autora, que teria tido como um de seus muitos efeitos a multiplicação de agentes profissionais da moda e o surgimento de outros espaços de consagração. Embora os desfiles, sob forma das semanas de moda, ainda desempenhem um papel central em termos simbólicos e efetivos, Michetti, retomando uma série de autores que se debruçam sobre a história da moda, nos mostra quanto outros atores e outras esferas de consagração alteraram esse campo, ressaltando a importância das feiras têxteis e dos bureaux de estilo na construção de tendências mundiais.

Ao encontro dessas transformações, a própria internacionalização teria também alterado profundamente o campo da moda. A autora retrata, assim, de modo detaIhado, os processos de internacionalização da moda europeia, seu peso e importância diante da emergência de outros centros produtores, noutras regiões do planeta, sobretudo a partir de fluxos globais vindos das Américas e da Ásia. Diversificação, descentralização e mundialização seriam, desse modo, no macrocenário esboçado por Michetti, algumas das consequências desses processos descritos como tendo lugar ao longo do século XX.

Aproximando-se da história da moda no Brasil, a socióloga também procura analisar como se deu a constituição de um campo da moda no país, a importância da Europa e da França na difusão de modas também aqui nos trópicos, e como foi se alterando a relação das modas nacionais com as estrangeiras. Embora um esforço semelhante já tenha sido empreendido por outros pesquisadores brasileiros no que diz respeito à análise histórica da relação Brasil versus estrangeiro no campo da moda, 0 trabalho de Michetti aponta de maneira mais específica para os anos de 1990 como fundamentais para o crescimento do mercado nacional de moda no país, de um lado, e a entrada competitiva da moda brasileira num contexto global, de outro.

Essa análise dos contextos macro econômicos e históricos, no que diz respeito à formação da moda internacional e da moda brasileira, encontra-se no livro esboçada de forma clara e sintética, fazendo dele uma boa obra de referência para estudantes de cursos de moda e demais interessados em encontrar uma produção acadêmica em português que de forma sucinta dê conta desses processos.

Com relação ao surgimento de uma moda nacional no Brasil, a autora aponta a relevância histórica de eventos como a Feira Nacional da Indústria Têxtil (Fenit), objeto de reflexão aprofundada de Bonadio (2005) em sua tese de doutorado. Mais contemporaneamente, a criação de semanas de moda em cidades como Rio de Janei- 
ro e São Paulo, que na chave argumentativa de Miqueli Michetti seriam entendidas como capitais locais da moda internacional, também teria fundamental importância para o desenvolvimento da moda brasileira. Ainda no que concerne à sua internacionalização, a criação da feira Première Vision São Paulo é analisada pela autora como uma espécie de ponto crítico, representando uma chancela francesa e global à moda que se produz por aqui, e sua realização no país como resultado do encontro entre 0 desejo de que a feira atue globalmente e as iniciativas de promover a moda brasileira para além das fronteiras nacionais.

Assim como procurei mostrar em minha tese de doutorado (LEITÃO, 2007), Miqueli Michetti aponta a criação e exploração do que podemos chamar de "brasilidade", por parte da moda nacional, como estratégia de reconhecimento no exterior. Tal estratégia estaria situada num quadro mais amplo de tensões e múltiplos agenciamentos entre globalização e florescimento das diferenças locais que, no caso brasileiro, conduziria a uma busca de identidade nacional por parte da moda com efeitos de diferenciação diante de outras tantas modas nacionais e busca de um lugar ao sol no campo da moda internacional.

A autora explora em seu livro de forma densa alguns dos caminhos que percebeu terem sido adotados nessa direção de recriação de uma identidade nacional brasileira, alguns deles que já se faziam presentes de maneira significativa quando de minha pesquisa de campo em eventos de moda com participação brasileira na França em 2005, ano do Brasil na França. Discursos sobre miscigenação, diversidade étnica, mestiçagem, diversidade ambiental, jeitinho e criatividade brasileiros, são algumas entre as muitas representações acionadas nesse esforço de nacionalizar para internacionalizar. Outros elementos, como a exuberância natural de corpos e paisagens e um apelo

[136] à sensualidade e corporalidade supostamente típicas do Brasil, talvez tenham perdido um pouco de sua expressividade e eficácia simbólica nos anos subsequentes, pois não aparecem com as mesmas dimensões nos dados empíricos de Michetti.

Como uma reatualização transformadora desses estereótipos da nação trazidos à tona na construção de uma moda do Brasil, Michetti aponta para o viés de uma moda ética, sustentável e ecologicamente comprometida com uma direção que apresenta boa aderência com as noções de brasilidade exploradas pela moda nacional. A autora também sublinha que o discurso da brasilidade não é unânime entre os criadores de moda brasileiros, e que um "bom uso da brasilidade" é uma questão que se coloca frequentemente para esses atores. A própria ideia de que poderia haver tal coisa como um bom ou mau uso da brasilidade deve ser, no entanto, problematizada, pois mais parece funcionar como categoria acusatória no interior do próprio campo e nas lutas simbólicas que nele se estabelecem. Nesse mesmo sentido, Michetti aponta para 0 fato de que tal discurso sobre brasilidade não é uma constante, sendo ativado e desativado conforme situações específicas.

\section{REFERÊNCIAS}

BONADIO, Maria Cl'Audia. O fio sintético é um show:moda, política e publicidade. Campinas, 2005. Tese (Doutorado em História) - Unicamp. 